\title{
Trends in HIV Prevalence in Pregnant Women in Rural South Africa
}

\author{
Ayesha B. M. Kharsany, PhD, * Janet A. Frohlich, DCur, * Nonhlanhla Yende-Zuma, MS,* \\ Gethwana Mahlase, BCur, $†$ Natasha Samsunder, BTech,* Rachael C. Dellar, MS,* \\ May Zuma-Mkhonza, BCur, $\neq$ Salim S. Abdool Karim, MBChB, PhD, ${ }^{*} \xi$ and \\ Quarraisha Abdool Karim, $P h D^{*} \xi$
}

Background: Despite substantial progress in the delivery of HIV prevention programs, some communities continue to experience high rates of HIV infection. We report on temporal trends in HIV prevalence in pregnant women in a community in rural KwaZuluNatal in South Africa.

\begin{abstract}
Methods: Annual, anonymous cross-sectional HIV sero-prevalence surveys were conducted between 2001 and 2013 among first visit prenatal clinic attendees. The time periods 2001 to 2003 were defined as pre-antiretroviral therapy (ART), 2004 to 2008 as early ART, and 2009 to 2013 as contemporary ART roll-out, to correspond with the substantial scale-up of ART program.
\end{abstract}

Results: Overall, HIV prevalence rose from 35.3\% [95\% confidence interval (CI): 32.3 to 38.3] pre-ART (2001-2003) to $39.0 \%$ (95\% CI: 36.8 to 41.1 ) in the early ART (2004-2008) to $39.3 \%(95 \%$ CI: 37.2 to 41.4$)$ in the contemporary ART (2009-2013) roll-out periods. In teenage women $(<20$ years), HIV prevalence declined from $22.5 \%$ (95\% CI: 17.5 to 27.5 ) to $20.7 \%$ (95\% CI: 17.5 to 23.8 ) and to $17.2 \%$ (95\% CI: 14.3 to 20.2$)$ over the similar ART roll-out

Received for publication January 9, 2015; accepted May 21, 2015.

From the *Centre for the AIDS Programme of Research in South Africa (CAPRISA), Nelson R Mandela School of Medicine, University of KwaZulu-Natal, Durban, South Africa; †Zimnandi Zonke, Pietermaritzburg, South Africa; ‡uMgungundlovu Health District (D22), KwaZuluNatal Provincial Department of Health; and §Department of Epidemiology, Mailman School of Public Health, Columbia University, New York, NY.

Supported by the Centre for the AIDS Programme of Research in South Africa (CAPRISA), which was established as part of the Comprehensive International Program of Research on AIDS (CIPRA), and the National Institute of Allergy and Infectious Diseases (NIAID), National Institutes of Health (NIH), US Department of Health and Human Services (DHHS) (Grant \# 1U19 AI51794), and The US President's Emergency Plan for AIDS Relief (PEPFAR) (Grant \# 5U2GPS001350). J.A.F., A.B.M.K., N.Y.-Z., and G.M. were supported by the Columbia University-Southern African Fogarty AIDS International Training and Research Program (AITRP) and funded by the Fogarty International Center, National Institutes of Health (Grant \# D43TW00231). A.B.M.K. was also supported in part by the SA Medical Research Council.

The remaining authors have no funding or conflicts of interest to disclose.

Supplemental digital content is available for this article. Direct URL citations appear in the printed text and are provided in the HTML and PDF versions of this article on the journal's Web site (www.jaids.com).

Correspondence to: Ayesha B. M. Kharsany, PhD, CAPRISA, 2nd Floor, Doris Duke Medical Research Institute, Nelson R Mandela School of Medicine, University of KwaZulu-Natal, Private Bag 7, Congella 4013, Durban, South Africa (e-mail: Ayesha.kharsany@caprisa.org).

Copyright ( 2015 Wolters Kluwer Health, Inc. All rights reserved. periods $(P=0.046)$. Prevalence increased significantly in women 30 years and older $(P<0.001)$ over the same time period largely because of survival after ART scale up. Teenage girls with male partners of age $20-24$ and $\geq 25$ years had a 1.7 -fold $(95 \% \mathrm{CI}$ : 1.3-2.4; $P=0.001)$ and 3-fold (95\% CI: 2.1 to $4.3 ; P<0.001)$ higher HIV prevalence respectively.

Conclusions: Notwithstanding the encouraging decline in teenagers, the ongoing high HIV prevalence in pregnant women in this rural community, despite prevention and treatment programs, is deeply concerning. Targeted interventions for teenagers, especially for those in age-disparate relationships, are needed to impact this HIV epidemic trajectory.

Key Words: HIV, prevalence, young pregnant women, rural South Africa

(J Acquir Immune Defic Syndr 2015;70:289-295)

\section{INTRODUCTION}

In 2012, the Joint United Nations Program on HIV/ AIDS estimated that approximately 6.1 million (95\% CI: 5.8 to 6.4 million) people in South Africa were living with HIV, having the highest burden of infection in the world despite being home to $<1 \%$ of the global population. ${ }^{1}$ The epidemic in South Africa, that also has the highest number of AIDS cases globally, has been described as "hyper-endemic, generalized and mature." 2 Preventing further infections in such settings requires an in-depth understanding of the epidemic and to design customized locally responsive interventions accordingly. ${ }^{3-5}$

Since 2002, the 2-dose nevirapine regimen to prevent mother to child transmission of HIV has been available to all pregnant HIV sero-positive women who choose to have an HIV test and accept the prevention of mother to child transmission intervention. Parallel to these services, through the district hospitals, the South African Ministry of Health, initiated antiretroviral therapy (ART) provision to HIVpositive adults, meeting the ART eligibility criteria of CD4 cell count of $<200 / \mu \mathrm{L}$. By March 2005, at least one service point for AIDS-related care and treatment was established in each of the country's 53 districts. By 2008 about 588,000 people had initiated $\mathrm{ART}^{6}$; and contemporary ART roll-out continued to improve, with almost 2 million adults and children receiving ART in 2011, representing just over 50\% 
of those eligible for treatment under World Health Organization guidelines of CD4 cell count of $<350 / \mu \mathrm{L}$. ${ }^{7,8}$

In 2004, the Centre for the AIDS Programme of Research in South Africa (CAPRISA) through its research facilities in rural Vulindlela, uMgungundlovu district, KwaZulu-Natal (KZN) initiated the free provision of ART to patients with AIDS, who met the eligibility criteria defined by the Department of Health. ${ }^{9}$ Over time, the decentralization of services and nurse-initiated management of ART through primary health care clinics facilitated the roll-out, scale up, and the retention of patients in ART programs. In parallel, the burden of managing uncomplicated cases at referral hospitals also reduced. To enhance the rapid scale-up of ART, mobile teams help to initiate patients at hard to reach areas such as farms, and for those having difficulty leaving their work premises to attend clinics. Community care givers play an important role and actively assist with tracing patients who default treatment, and have been successful in reintroducing them back to the health facilities. Through this comprehensive and incremental approach, the highest HIV burden district of uMgungundlovu made remarkable progress on ART provision and the number of patients on ART increased from 61,230 in $2011^{10}$ to 111,691 by $2014 .{ }^{11}$

To monitor temporal trends in the evolving epidemic, the South African government has undertaken annual, anonymous, HIV prevalence surveys among pregnant women utilizing public sector prenatal clinics. ${ }^{12}$ These and other data ${ }^{13}$ have highlighted the differences within and between South African provinces, with the province of KZN having the highest prevalence of HIV. ${ }^{14}$ As epidemics mature with increasing coverage of ART, prevalence of HIV infection is a less reliable marker of the evolving epidemic, since survival improves, and prevalence is expected to increase and mask new infections. However, measuring HIV prevalence in young, pregnant women $<24$ years, provides a reliable indirect measurement of new infections, as they are more likely to have recently become sexually active, and therefore infection is more likely to be recent. Since 2001, we have conducted complementary annual HIV prevalence surveys in prenatal clinics in rural KZN in one of the 3 highest burden HIV health districts ${ }^{12}$ where extensive HIV prevention and treatment programs are being implemented. The purpose of this study was to assess the trends in HIV prevalence in pregnant women after the introduction and scale-up of ART, and selected risk factors associated with HIV transmission in this setting.

\section{METHODS}

\section{Study Setting}

Surveys were undertaken in Vulindlela, a rural community located about $150 \mathrm{~km}$ west of Durban in the province of KZN, home to approximately 150,000 residents and characterized by high levels of poverty and unemployment.

Health care in Vulindlela is accessed from 7 nurse-run primary health care clinics that deliver an essential package of health services that includes prenatal care, family planning, childhood immunization, minor ailment services,

290 | www.jaids.com and management of common chronic conditions at no cost. HIV testing services are available at these clinics with preand post-test counseling.

\section{Study Procedures}

The South African Department of Health's National Antenatal Sentinel HIV and Syphilis Prevalence Surveys are conducted annually among pregnant women, and blood samples are tested using a single enzyme-linked immunosorbent assay (ELISA) (Abbott Axsym System for HIV-1/HIV-2; Abbott Laboratories, Chicago, IL).

Coinciding with these surveys, we conducted cross sectional surveys from October 1 st to November 30th of each year from 2001 to 2013. Consecutive pregnant women who presented for their first prenatal care visit at one of the 7 primary health care clinics, regardless of age were eligible to participate.

All women were provided with study information on anonymized HIV testing for surveillance. As part of routine prenatal care, blood samples are collected for hemoglobin and syphilis testing, and women were requested to provide an additional sample for HIV testing. During each survey, after verbal informed consent, trained nurses administered a questionnaire to obtain minimal key demographic and behavioral data. This included the age of the woman, her current partner's age, if this was her first pregnancy, and dates of prior pregnancies, knowledge of HIV status, and exposure to antiretroviral therapy (ART).The details were recorded on a standardized case report form labelled with a unique participant identification number. Peripheral blood was collected in prelabelled EDTA and plain tubes. Samples were transported to the central laboratory in Durban for HIV testing after removal of all identifiers. With the aid of a unique participant identification number, HIV test results were linked to demographic and behavioral data; from 2004 to current partner's age and prior pregnancies, and from 2009 to exposure to ART. The survey protocol was in compliance with the World Health Organization's and South African Department of Health's guidelines for the conduct of anonymized HIV surveys, ${ }^{12,15-17}$ and was reviewed and approved by the University of KwaZulu-Natal Biomedical Research Ethics Committee (Reference number E179/04).

\section{Laboratory Testing Procedures}

In 2001 and 2002, HIV testing was performed using ELISA (Abbott AxSYM system for HIV-1/HIV-2; Abbott Laboratories). In 2003, specimens were tested using a rapid assay (Abbott Determine, Abbott Park, IL) with all positives confirmed using a second rapid assay (Capillus, Trinity Biotech, Bray, Wicklow, Ireland). From 2004 to 2013, specimens were tested by ELISA (Enzygnost, Dade Behring, Mannheim, Germany). Any specimen indicating an indeterminate result was further tested with the Abbott Determine rapid assay. All these tests perform similarly with sensitivities and specificities in excess of $98 \% .^{18}$

Copyright (C) 2015 Wolters Kluwer Health, Inc. All rights reserved. 


\section{Data Analysis}

Data were analyzed using SAS version 9.3 (SAS Institute, Cary, NC). All statistical tests are 2 sided and CIs are at $95 \%$ level. Based on consistency in the age structure of the cohort over time, pooled summary data for women are reported for the time periods 2001 to 2003 (as pre-ART rollout), 2004 to 2008 (early ART roll-out), and 2009 to 2013 (contemporary ART roll-out) to correspond with the delivery of the ART program in KZN. ${ }^{7}$

The overall HIV prevalence and 95\% CI were calculated and reported for age stratified groups. The CochranArmitage $\chi^{2}$ test was used to test for linear trend in HIV prevalence over time. Log-binomial regression adjusted for previous pregnancy and clinic was used to determine whether the age of current male sexual partner was associated with HIV infection in women. We included the clinic in the model to adjust for clustering because the clinics were of different sizes and HIV prevalence varied across clinics. We assumed that women who had been pregnant before were at high risk of HIV, and that previous pregnancy could confound age and HIV status. This analysis was stratified by the women's age groups $<20,20-24$ and $\geq 25$ years.

\section{RESULTS}

\section{Demographic Characteristics}

Between 2001 and 2013, a total of 5075 pregnant women attending prenatal clinics in the rural Vulindlela sub district of KZN were included in annual HIV prevalence surveys, with a mean of 390 (range 225-552) women surveyed per year.

The age distribution of surveyed women attending prenatal clinics showed that the proportion of women in the $<20$ year age group was $33.7 \%$ in the $2001-2003$ period, $32.9 \%$ in the $2004-2008$ period, and $30.6 \%$ in the 2009-2013 period and was the highest compared to other age groups. The proportion of women aged 20-24 years increased from $28.1 \%$ in the $2001-2003$ period to $30.3 \%$ in the period $2004-2008$ and was $29.3 \%$ in the $2009-2013$ period. However, the proportion of women in the age groups $25-29,30-34$, and $\geq 35$ years was consistently lower across all time periods (see Table S1, Supplemental Digital Content, http://links.lww.com/QAI/A718).

\section{Temporal Trends in HIV Prevalence}

Table 1 shows the overall and age specific HIV prevalence. The overall HIV prevalence increased from $35.3 \%$ (95\% CI: 32.3 to 38.3 ) in the period 2001-2003 to $39.0 \%$ (95\% CI: 36.8 to 41.1 ) in the period 2004-2008 and to $39.3 \%$ (95\% CI: 37.2 to 41.4$)$ in the $2009-2013$ period; $(P=0.058)$. Age-stratified analysis showed that HIV prevalence in teenagers $<20$ years was $22.5 \%$ (95\% CI: 17.5 to 27.5 ) in the 2001-2003 period and decreased to $20.7 \%$ (95\% CI: 17.5 to 23.8 ) in the period 2004-2008 and to $17.2 \%$ (95\% CI: 14.3 to 20.2 ) in the $2009-2013$ period; $(P=0.046)$. Similarly, in women in the $20-24$ year age group, the prevalence was $45.5 \%$ (95\% CI: 38.9 to 52.0 ) in the period 2001-2003 and declined to $44.2 \%$ (95\% CI: 40.2 to 48.2$)$ in the period $2004-2008$ and to $37.9 \%(95 \%$ CI: 34.0 to 41.8$)$ in the period 2009-2013; $(P=0.018)$. In women aged 25-29 years, HIV prevalence remained relatively constant and was $47.9 \%(95 \% \mathrm{CI}: 40.3$ to $55.5), 58.8 \%$ (95\% CI: 53.5 to 64.2$)$, and $57.6 \%(95 \%$ CI: 52.7 to 62.4$) ;(P=0.085)$ over the same time period. Among women 30-34 years, HIV prevalence increased from $26.7 \%$ (95\% CI: 16.7 to 36.7$)$ to $55.5 \%$ (95\% CI: 49.0 to 62.0$)$ and to $59.9 \%$ (95\% CI: 53.9 to 66.0$)$; $(P<0.001)$, and in women 35 years and older HIV prevalence increased from $27.4 \%$ (95\% CI: 16.3 to 38.5 ) to $30.8 \%$ (95\% CI: 23.8 to 37.7$)$ and to $53.4 \%$ (95\% CI: 46.0 to 60.8$)$; $(P<0.001)$ over the same time periods. Figure 1 shows the decline in HIV prevalence in the $<20$ and 20-24 year age group, with prevalence increasing in the $25-29,30-34$ and $\geq 35$ year age groups.

The trends in HIV prevalence in young women are presented in 2-year age groups in Table 2. Given that HIV infection in women $<24$ years could be regarded as a reliable measure of incident infections, ${ }^{19}$ thus has substantial bearing on assessing epidemic control progress in terms of reducing new infections. ${ }^{19}$ In all survey periods, a substantial increase in HIV prevalence was observed as women transitioned from their late teens to early twenties (Table 2). Substantial reductions in HIV prevalence from $22.2 \%$ (95\% CI: 12.6 to 31.8 ) to $10.6 \%$ (95\% CI: 6.0 to 15.2$)$ and to $7.7 \%$ (95\% CI: 3.7 to 11.8$) ;(P=0.003)$ were observed in the $\leq 16$ year olds, but rapid increase in HIV prevalence from age 17 years and over were common to all study periods, with little variation over time. In this setting, by age 24 years, $54.4 \%(95 \% \mathrm{CI}$ : 43.4 to 65.4$), 51.1 \%$ (95\% CI: 43.9 to 58.2$)$ and $46.3 \%$ (95\% CI: 39.6 to 52.9$)$; $(P=0.176)$ of young pregnant women were HIV-positive in the periods 2001-2003, 2004-2008 and 2009-2013, respectively.

\section{Temporal Trends in Sexual Partner Age Disparity and HIV Prevalence}

Data on age disparity, in the sexual relationships engaged by surveyed pregnant women were collected from 2003 , and was available for 4160 women $(82.0 \%)$. Overall, between 2003 and 2013, HIV prevalence was higher in women who reported currently having older sexual partners compared with those having partners either the same age or younger than themselves. Table 3 shows the association between current sexual partner's age and HIV infection stratified by woman's age. Among teenagers $<20$ years, the adjusted relative risk (ARR) for HIV infection with current sexual partner in the age group 20-24 years was $1.7(95 \%$ CI: 1.3 to 2.4$) ;(P=0.001)$ and increased to $3.0(95 \% \mathrm{CI}: 2.1$ to 4.3$)$; $(P<0.001)$ if the current sexual partner was $\geq 25$ years. For young women aged 20-24 years whose current sexual partner was $<20$ years, the ARR was $0.3(95 \%$ CI: 0.1 to 1.2$) ;(P=0.097)$, but increased significantly to 1.3 (95\% CI: 1.2 to 1.6$) ;(P<0.001)$ with a partner $\geq 25$ years. In contrast, for women $\geq 25$ years, the age of the current sexual partner was not associated with HIV infection; $\mathrm{ARR}=1.0(95 \% \mathrm{CI}: 0.7$ to 1.5$) ;(P=0.869)$. 
TABLE 1. Temporal Trends in HIV Prevalence by Age in Pregnant Women Attending Prenatal Clinics in Vulindlela, Rural KwaZuluNatal by Survey Periods 2001-2003, 2004-2008, and 2009-2013

\begin{tabular}{|c|c|c|c|c|c|c|c|}
\hline \multirow[b]{2}{*}{ Age Group } & \multicolumn{2}{|c|}{ 2001-2003 } & \multicolumn{2}{|c|}{ 2004-2008 } & \multicolumn{2}{|c|}{ 2009-2013 } & \multirow[b]{2}{*}{$P^{*}$} \\
\hline & $\mathbf{n} / \mathbf{N}$ & $\%(95 \% \mathrm{CI})$ & $\mathbf{n} / \mathbf{N}$ & $\%(95 \% \mathrm{CI})$ & $\mathbf{n} / \mathbf{N}$ & $\%(95 \%$ CI $)$ & \\
\hline$<20$ & $60 / 267$ & $22.5(17.5$ to 27.5$)$ & $133 / 644$ & 20.7 (17.5 to 23.8$)$ & $109 / 633$ & 17.2 (14.3 to 20.2$)$ & 0.046 \\
\hline $20-24$ & $101 / 222$ & 45.5 (38.9 to 52.0$)$ & $262 / 593$ & 44.2 (40.2 to 48.2$)$ & $230 / 607$ & 37.9 (34.0 to 41.8$)$ & 0.018 \\
\hline $25-29$ & $79 / 165$ & $47.9(40.3$ to 55.5$)$ & $190 / 323$ & $58.8(53.5$ to 64.2$)$ & $232 / 403$ & $57.6(52.7$ to 62.4$)$ & 0.085 \\
\hline $30-34$ & $20 / 75$ & 26.7 (16.7 to 36.7$)$ & $126 / 227$ & $55.5(49.0$ to 62.0$)$ & $151 / 252$ & $59.9(53.9$ to 66.0$)$ & $<0.001$ \\
\hline$\geq 35$ & $17 / 62$ & 27.4 (16.3 to 38.5$)$ & $52 / 169$ & $30.8(23.8$ to 37.7$)$ & $94 / 176$ & $53.4(46.0$ to 60.8$)$ & $<0.001$ \\
\hline
\end{tabular}

*Cochran-Armitage $\chi^{2}$ test for linear trend.

$\dagger$ Includes women with missing age.

\section{DISCUSSION}

Our surveys highlight the consistently high burden of HIV infection borne by young pregnant women in this rural community, which may be explained at least in part by young women engaging in high-risk sexual intercourse. HIV prevalence has remained unprecedentedly high: in excess of $40 \%$ in women aged $20-24$ years, and in excess of $50 \%$ in women aged 25-34 years. The overall high prevalence in this age group is deeply concerning despite the prevention and treatment programs, and additional targeted interventionsespecially for those in age-disparate relationships - are needed to impact this HIV epidemic.

Although the roll-out of ART in 2004 in this community appears to have had a substantial impact on survival, agespecific HIV prevalence provides a clear explanation for lack of progress in reducing the disease burden despite the presence of numerous prevention interventions. Although there has been a significant decline in HIV prevalence in the $\leq 16$ year age group, indeed, we report exceptionally high and relatively unchanged HIV prevalence in young women $(17.2 \%$ in women $<20$ years in the 2009-2013 study period), which suggests that reductions in new infections in this population have been minimal, given that in generalized epidemic settings such as South Africa, HIV prevalence in 15-24-year -olds is considered a reliable measurement to approximate trends in incident infections. ${ }^{19,20}$ Assuming that HIV transmission is highest during early and acute HIV infection, the burden of potential incident infections in these teenagers and young women is deeply concerning, and has serious implications for fueling the HIV epidemic in this community, ${ }^{21-24}$ though the slight declines in HIV prevalence in the teenage groups are

FIGURE 1. Trends in HIV prevalence in pregnant women by survey period; 2001-2003, 2004-2008, and 2009-2013. promising against the existing sheer high burden of infection. Moreover, significantly altering epidemic trajectories in similar settings will require prevention interventions targeted at teenagers and young women, and understanding the risk factors associated with HIV acquisition in this key population.

The association reported here between high HIV prevalence and increased age of sexual partners for women $\leq 24$ years, which increases in strength in women $<20$ years of age is consistent with other reports. ${ }^{13,25-29}$ There is an urgent need to understand the causality of this association and how it is evolving with time, and the reasons why teenagers and young women in this community engage sexually with older men. To what extent partnerships leading to sexual intercourse are impacted by the need for financial support in young women, illness and death in women over 25 years, and other complex cultural factors is undetermined. ${ }^{26}$

Furthermore, monitoring the impact of ART provision and the survival of women over 25 years continues to be critical; the high burden of HIV observed in this age group reflects the cumulative effect of HIV acquisition, underscores the extent of the care burden, and may help inform future prevention and treatment efforts. Although HIV prevalence in South Africa varies widely by province and the generalizability of results is limited, our surveys starkly demonstrate the unprecedented scale of the HIV epidemic at a local level. The surveys also provide some bearing on the implications of the epidemic for the community. For example, the low proportion of pregnancies in the pre-ART roll-out period (2001-2003) in women over 30 years reported here, may be attributable to declines in fertility rate as a result of advancing HIV disease, and high mortality rates in this group. ${ }^{30-34}$

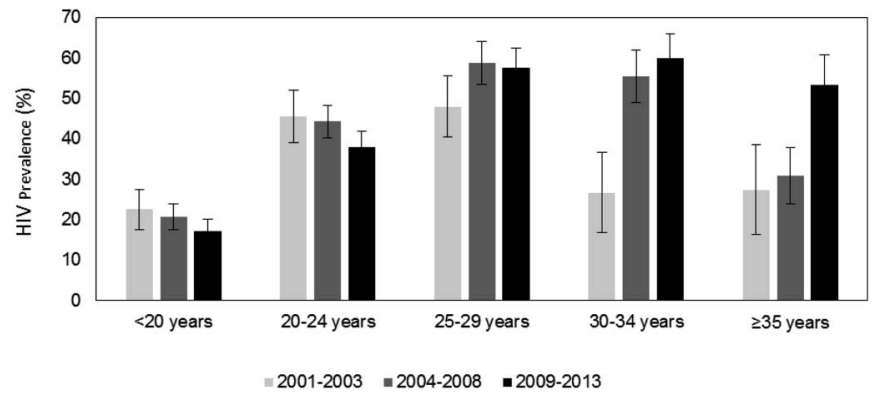

Copyright (C) 2015 Wolters Kluwer Health, Inc. All rights reserved. 
TABLE 2. Temporal Trends in HIV Prevalence in $\leq 24$ Year Old Pregnant Women Attending Prenatal Clinics in Vulindlela, Rural KwaZulu-Natal by Survey Periods 2001-2003, 2004-2008 and 2009-2013

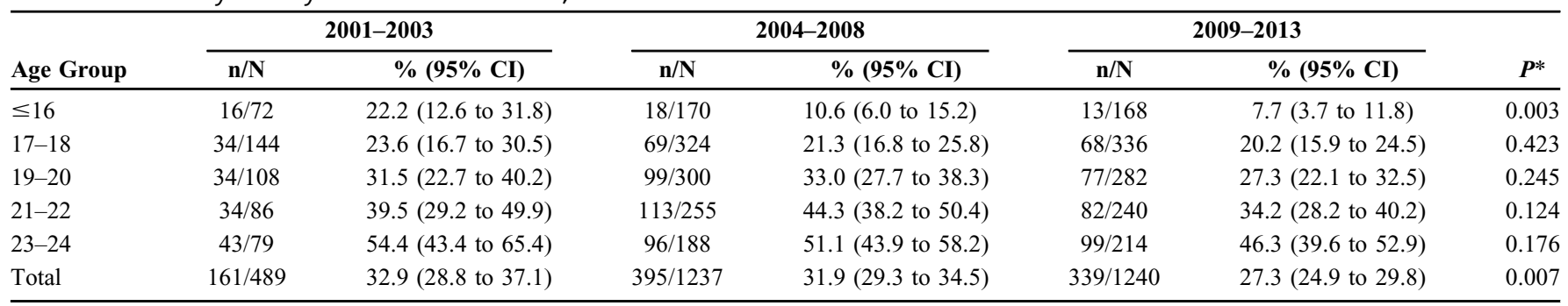

*Cochran-Armitage $\chi^{2}$ test for linear trend.

In this setting, HIV acquisition is almost synonymous with sexual debut, which is estimated at around age 16 years. ${ }^{27,35}$ Further, the burden of teenage pregnancies in the community, which represent an average of $30 \%$ of the surveyed pregnancies sampled per year from 2001 to 2013, is concerning, given associations with poor economic and educational outcomes. ${ }^{27,36}$ Although several, largely government-initiated and school-based behavioral interventions and educational outreach programs have aimed to target the teenage female population, these data demonstrate their limited success in terms of reducing pregnancy and HIV infection rates in teenagers. Despite several behavioral interventions currently implemented to reduce the sexual transmission of HIV, including programs aimed at delaying sexual debut, preventing intergenerational sex, medical male circumcision, promoting condom use within the structured $\mathrm{ABC}$ guidelines (abstinence, being faithful to one's partner, and condom use), and even with earlier access to ART, which has been shown to prevent HIV transmission in randomized clinical trials ${ }^{37}$ and observational cohorts, ${ }^{38}$ HIV incidence and prevalence remains persistently high in teenage girls. ${ }^{39-41}$ It is clear that these teenage girls are a key group for HIV prevention, and understanding of HIV transmission dynamics in this population is a major gap in the knowledge of HIV epidemiology. The severity of the epidemic in this setting creates an imperative for the inclusion of teenagers $<18$ years in biomedical trials ${ }^{42}$ with both HIV incidence and other sexual and reproductive health endpoints.

There are several limitations to our study. Our survey population comprising pregnant women seeking prenatal care limits generalizability beyond this group, as HIV prevalence is likely to be very different among similar age, nonpregnant women in this community. ${ }^{43}$ Furthermore, pregnant women attending the clinic for the first time for a current pregnancy are provided with comprehensive health care and we included all women in the study; however, it is possible that some women might have been missed and therefore the prevalence could potentially be overestimated. The subgroup analysis on the association between the current sexual partner's age and HIV infection stratified by woman's age, although limited by the small sample size across each year, demonstrated that this effect is more distinct in teenagers $<20$ years. However, as women get older it is not clear whether boys and younger men are at risk of infection from older women. More detailed phylogenetic analysis of HIV-1 sequences and phylodynamic studies are needed to better understand the precise bidirectionality of infection to sexual partners across all age groups. As surveillance spanned over several years, the

TABLE 3. Multiple Log Binomial Regression Examining the Association of Current Partner's Age and HIV Infection Among Pregnant Women attending Prenatal Clinics in Rural KwaZulu-Natal, 2003-2013. Unadjusted and Adjusted Relative Risk, 95\% Cl for Prevalent HIV Infection

\begin{tabular}{|c|c|c|c|c|c|c|}
\hline \multirow[b]{2}{*}{ Age Group } & \multirow[b]{2}{*}{ Partner's Age Group } & \multirow{2}{*}{$\begin{array}{c}\text { HIV Prevalence } \\
\%(95 \% \mathrm{CI})\end{array}$} & \multicolumn{2}{|c|}{ Unadjusted } & \multicolumn{2}{|c|}{ Adjusted* } \\
\hline & & & RR (95\% CI) & $P$ & $\overline{\text { ARR (95\% CI) }}$ & $P$ \\
\hline \multirow[t]{3}{*}{$<20$} & $<20$ & $10.8(7.8$ to 13.7$)$ & Reference & & - & \\
\hline & $20-24$ & $20.4(17.5$ to 23.3$)$ & $1.9(1.4$ to 2.6$)$ & $<0.001$ & $1.7(1.3$ to 2.4$)$ & 0.001 \\
\hline & $\geq 25$ & 32.9 (25.3 to 40.4$)$ & $3.1(2.1$ to 4.4$)$ & $<0.001$ & $3.0(2.1$ to 4.3$)$ & $<0.001$ \\
\hline \multirow[t]{3}{*}{$20-24$} & $<20$ & $10.0(0.0$ to 23.1$)$ & $0.3(0.1$ to 1.1$)$ & 0.062 & $0.3(0.1$ to 1.2$)$ & 0.097 \\
\hline & $20-24$ & $35.1(31.0$ to 39.2$)$ & Reference & & - & \\
\hline & $\geq 25$ & $46.6(42.9$ to 50.3$)$ & $1.3(1.2$ to 1.5$)$ & $<0.001$ & $1.3(1.2$ to 1.6$)$ & $<0.001$ \\
\hline \multirow[t]{3}{*}{$\geq 25$} & $<20$ & 0 & $\mathrm{NE}$ & & & \\
\hline & $20-24$ & $57.7(38.7$ to 76.7$)$ & $1.1(0.8$ to -1.5$)$ & 0.714 & $1.0(0.7$ to 1.4$)$ & 0.869 \\
\hline & $\geq 25$ & $54.2(51.8$ to 56.7$)$ & Reference & & - & \\
\hline
\end{tabular}

*Adjusted for clinic and previous pregnancy.

ARR, adjusted relative risk; NE, non estimable; RR, unadjusted relative risk. 
outcome measurement of HIV sero-positivity could potentially be misclassified because of the use of different laboratory methods and tests, even though these tests have a sensitivity and specificity in excess of $98.2 \%$ and have been used extensively in national surveillance programs. ${ }^{13,44,45}$ Nevertheless it is possible that these tests may yield nonspecific reactions due to causes other than HIV, in low or high HIV prevalence settings and therefore have the risk of misclassification. Although we aimed to collect data on ART use from 2009, we obtained a low response rate which could be due to HIV-related stigma and discriminations, which remain pervasive in this community. ${ }^{46-49}$ We therefore relied on the district ART data. ${ }^{10,11}$

To conclude, notwithstanding limitations inherent in cross-sectional surveys and with behavioral data collection specifically of women's recall bias of their partner's age, these data demonstrate an unequivocal and unambiguously high pregnancy rate and HIV prevalence in this rural community, and highlight partner age as an important risk factor in HIV acquisition among young women. Given the 8-10 year latency between HIV infection and AIDS related morbidity and mortality, ${ }^{50}$ the continued scale-up of ART services at primary health care clinics could be key to averting a further AIDS catastrophe in this setting. To what extent survival of these communities, already with limited economic and productive capacity, is compromised, is hard to predict. Inclusion of young women in our quest for new biomedical and behavioral modalities to reduce HIV risk remains an urgent imperative.

\section{ACKNOWLEDGMENTS}

The authors thank all the women who participated and the clinic staff that assisted in these surveys. A special thanks to the Provincial Department of Health for their support.

\section{REFERENCES}

1. Joint United Nations Programme on HIV/AIDS (UNAIDS). Global report: UNAIDS report on the global AIDS epidemic, 2013. Available at: http:// www.unaids.org/en/media/unaids/contentassets/documents/epidemiology/ 2013/gr/UNAIDS_Global_Report_en.pdf. ISBN 978-92-9253-032-7. Accessed December 10, 2014.

2. Abdool Karim Q, Hassanally L. HIV epidemic types and customized prevention responses. Focus. 2008;23:1-4.

3. Chopra M, Lawn JE, Sanders D, et al. Achieving the health millennium development goals for South Africa: challenges and priorities. Lancet. 2009;374:1023-1031.

4. Wilson D, Halperin DT. "Know your epidemic, know your response": a useful approach, if we get it right. Lancet. 2008;372:423-426.

5. Collins C, Coates TJ, Curran J. Moving beyond the alphabet soup of HIV prevention. AIDS. 2008;22(suppl 2):S5-S8

6. Adam MA, Johnson LF. Estimation of adult antiretroviral treatment coverage in South Africa. S Afr Med J. 2009;99:661-667.

7. Johnson LF. Access to antiretroviral treatment in South Africa, 2004 2011. S Afr J HIV Med. 2012;13:22-27.

8. South African National Department of Health. Department of Health Annual Report 2012/13. Available at: http://africacheck.org/wp-content/ uploads/2014/02/131016dohrreport.pdf. RP: 237/2012, ISBN: 978-0621-41127-0. Accessed December 10, 2014.

9. Naranbhai V, Abdool Karim Q, Naidoo K, et al. Sustainability of taskshifting for antiretroviral treatment. Lancet. 2012;380:1907-1908.

10. HIV/AIDS Quarterly Report. KwaZulu Natal Province. uMgungundlovu district. 2012. Available at: http://www.google.co.za/url?sa=t\&rct=j\& $\mathrm{q}=\&$ esrc $=\mathrm{s} \&$ frm $=1 \&$ source $=$ web $\& \mathrm{~cd}=2 \& \mathrm{ved}=0 \mathrm{CCIQFjAB \& url}=\mathrm{http} \%$ 3A\%2F\%2Fwww.umdm.gov.za\%2Findex.php\%3Foption\%3Dcom_docman $\%$ 26task\%3Ddoc_download\%26gid\%3D751\%26Itemid\%3D382\&; ei=emKuVIz9AYLmaumCgpAM\&usg=AFQjCNEZ-XYUbrpR7YhCo9f2 lzJYEF7M9w. Accessed December 20, 2014.

11. uMgungundlovu District Presentation Quarter 2 2014/2015. 2014. uMgungundlovu District Municipality. Available at: http://www. kznonline.gov.za/hivaids/councils/Provincial-Councils-on-AIDS/2014/ uMgungundlovu\%20Q2\%202014\%202015.pdf. Accessed December 20, 2014.

12. South African Department of Health. The 2012 National Antenatal Sentinel HIV and Herpes Simplex type-2 Prevalence Survey, South Africa 2014. Available at: http://www.health.gov.za/docs/reports/2013/ report4.pdf. Accessed June 30, 2014.

13. Shisana O, Rehle T, Simbayi LC, et al. South African National HIV Prevalence, Incidence and Behaviour Survey, 2012. Cape Town, South Africa: HSRC Press; 2014.

14. Coetzer M, Cilliers T, Papathanasopoulos M, et al. Longitudinal analysis of HIV type 1 subtype C envelope sequences from South Africa. AIDS Res Hum Retroviruses. 2007;23:316-321.

15. UNAIDS/WHO. Guidelines for Second Generation HIV Surveillance: The Next Decade. Working Group on Global HIV/AIDS and STI Surveillance. World Health Organisation and Joint United Nations Programme on HIV/AIDS; 2000. http://www.who.int/hiv/pub/surveillance/ en/cds_edc_2000_5.pdf.

16. South African Department of Health. The South African National Voluntary Counselling and Testing (VCT) HIV Prevention and Care Strategy. Department of Health; Pretoria, South Africa; 2003.

17. South African National Department of Health. National HIV counselling and testing policy guidelines. 2010. Available at: http://www.uj.ac.za/ EN/CorporateServices/ioha/Documentation/Documents/hct_policy_ guidelines\%202010.pdf. Accessed December 10, 2014.

18. Sickinger E, Stieler M, Kaufman B, et al. Multicenter evaluation of a new, automated enzyme-linked immunoassay for detection of human immunodeficiency virus-specific antibodies and antigen. $J$ Clin Microbiol. 2004;42:21-29.

19. Ghys PD, Kufa E, George MV. Measuring trends in prevalence and incidence of HIV infection in countries with generalised epidemics. Sex Transm Infect. 2006;82(suppl 1):i52-i56.

20. UNAIDS/WHO. Report on the Global HIV/AIDS Epidemic. Joint United Nations Programme on HIV/AIDS (UNAIDS); 2008. "UNAIDS/0825E/ JC1510E” ISBN 97892917371162008 . http://data.unaids.org/pub/ GlobalReport/2008/jc1510_2008_global_report_pp1_10_en.pdf.

21. Abu-Raddad LJ, Longini IM Jr. No HIV stage is dominant in driving the HIV epidemic in sub-Saharan Africa. AIDS. 2008;22:1055-1061.

22. Laga M, Schwartlander B, Pisani E, et al. To stem HIV in Africa, prevent transmission to young women. AIDS. 2001;15:931-934.

23. Wawer MJ, Gray RH, Sewankambo NK, et al. Rates of HIV-1 transmission per coital act, by stage of HIV-1 infection, in Rakai, Uganda. J Infect Dis. 2005;191:1403-1409.

24. Quinn TC, Wawer MJ, Sewankambo N, et al. Viral load and heterosexual transmission of human immunodeficiency virus type 1. Rakai Project Study Group. N Engl J Med. 2000;342:921-929.

25. Gregson S, Nyamukapa CA, Garnett GP, et al. Sexual mixing patterns and sex-differentials in teenage exposure to HIV infection in rural Zimbabwe. Lancet. 2002;359:1896-1903.

26. Leclerc-Madlala S. Age-disparate and intergenerational sex in southern Africa: the dynamics of hypervulnerability. AIDS. 2008;22(suppl 4): S17-S25.

27. Pettifor AE, Rees HV, Kleinschmidt I, et al. Young people's sexual health in South Africa: HIV prevalence and sexual behaviors from a nationally representative household survey. AIDS. 2005;19:1525-1534.

28. Harling G, Newell ML, Tanser F, et al. Do age-disparate relationships drive HIV incidence in young women? Evidence from a population cohort in rural KwaZulu-Natal, South Africa. J Acquir Immune Defic Syndr. 2014;66:443-451.

29. Kelly RJ, Gray RH, Sewankambo NK, et al. Age differences in sexual partners and risk of HIV-1 infection in rural Uganda. $J$ Acquir Immune Defic Syndr. 2003;32:446-451.

30. Mashego M, Johnson D, Frohlich J, et al. High AIDS-related mortality among young women in rural KwaZulu-Natal. S Afr Med J. 2007;97: $587-592$.

Copyright (C) 2015 Wolters Kluwer Health, Inc. All rights reserved. 
31. Glynn JR, Buve A, Carael M, et al. Decreased fertility among HIV-1infected women attending antenatal clinics in three African cities. J Acquir Immune Defic Syndr. 2000;25:345-352.

32. Gray RH, Wawer MJ, Serwadda D, et al. Population-based study of fertility in women with HIV-1 infection in Uganda. Lancet. 1998;351:98-103.

33. Lewis JJ, Ronsmans C, Ezeh A, et al. The population impact of HIV on fertility in sub-Saharan Africa. AIDS. 2004;18(suppl 2):S35-S43.

34. Zaba B, Gregson S. Measuring the impact of HIV on fertility in Africa. AIDS. 1998;12(suppl 1):S41-S50

35. Shisana O, Rehle T, Simbayi L, et al. South African National HIV Prevalence, HIV Incidence, Behaviour and Communication Survey. HSRC Press; 2005. http://heaids.org.za/site/assets/files/1267/sabssm_iv_leo_final.pdf.

36. Jukes M, Simmons S, Bundy D. Education and vulnerability: the role of schools in protecting young women and girls from HIV in southern Africa. AIDS. 2008;22(suppl 4):S41-S56.

37. Cohen MS, Chen YQ, McCauley M, et al. Prevention of HIV-1 infection with early antiretroviral therapy. $N$ Engl J Med. 2011;365:493-505.

38. Donnell D, Baeten JM, Kiarie J, et al. Heterosexual HIV-1 transmission after initiation of antiretroviral therapy: a prospective cohort analysis. Lancet. 2010;375:2092-2098.

39. Abdool Karim Q, Kharsany AB, Frohlich JA, et al. Stabilizing HIV prevalence masks high HIV incidence rates among rural and urban women in KwaZulu-Natal, South Africa. Int J Epidemiol. 2011;40:922-930.

40. Abdool Karim Q, Kharsany AB, Leask K, et al. Prevalence of HIV, HSV-2 and pregnancy among high school students in rural KwaZuluNatal, South Africa: a bio-behavioral cross-sectional survey. Sex Transm Infect. 2014;90:620-626.

41. Kharsany AB, Mlotshwa M, Frohlich JA, et al. HIV prevalence among high school learners - opportunities for schools-based HIV testing programs and sexual reproductive health services. BMC Public Health. 2012;12:231
42. Abdool Karim Q, Kharsany AB, Frohlich JA, et al. HIV incidence in young girls in KwaZulu-Natal, South Africa-public health imperative for their inclusion in HIV biomedical intervention trials. AIDS Behav. 2012; 16:1870-1876.

43. Mmbaga EJ, Leyna GH, Mnyika KS, et al. Comparison of HIV-1 prevalence and risk factors between pregnant, non-pregnant, all women and the general population in Tanzania: implications for secondgeneration surveillance. Int J STD AIDS. National Department of Health, South Africa; 2009;20:483-488. http://www.health-e.org.za/wp-content/ uploads/2014/05/ASHIVHerp_Report2014_22May2014.pdf.

44. Shisana O, Simbayi L. Nelson Mandela/HSRC Study of HIV/AIDS. South African National HIV Prevalence, Behavioral Risks and Mass Media Household Survey 2002. Cape Town, South Africa: HSRC Press; 2002.

45. National Department of Health. The 2012 National Antenatal Sentinel HIV and Herpes Simplex Type-2 Prevalence Survey, South Africa. 2014.

46. Young SD, Hlavka Z, Modiba P, et al. HIV-related stigma, social norms, and HIV testing in Soweto and Vulindlela, South Africa: national institutes of Mental health Project accept (HPTN 043). J Acquir Immune Defic Syndr. 2010;55:620-624.

47. Peltzer K, Ramlagan S. Perceived stigma among patients receiving antiretroviral therapy: a prospective study in KwaZulu-Natal, South Africa. AIDS Care. 2011;23:60-68.

48. Abdool Karim SS. Stigma impedes AIDS prevention. Nature. 2011;474: $29-31$.

49. Karim QA, Meyer-Weitz A, Mboyi L, et al. The influence of AIDS stigma and discrimination and social cohesion on HIV testing and willingness to disclose HIV in rural KwaZulu-Natal, South Africa. Glob Public Health. 2008;3:351-365.

50. Munoz A, Sabin CA, Phillips AN. The incubation period of AIDS. AIDS 1997;11(suppl A):S69-S76. 